\title{
Apresentação do Dossiê Temático "Biblioteca e Arquivos Escolares"
}

Este dossiê temático da revista Educação em Foco é consagrado às questões relacionadas à biblioteca escolar, reconhecida tanto no meio acadêmico quanto por gestores e profissionais da educação como fundamental, quando se discutem práticas de leitura e de letramento na escola e a formação de leitores. No entanto, ainda há muito que se conhecer e que se propor acerca desse espaço e do que o constitui: acervos, organização, funções, práticas, mediações, dentre outros, além de ações políticas a ele voltadas.

Historicamente, a biblioteca sempre teve a sua função social reconhecida, sobretudo no que diz respeito às condições de acesso ao livro, à leitura e à informação. Se, em determinado tempo histórico, o acesso era restrito a determinadas classes abastadas da sociedade, posteriormente, com a crescente demanda pela democratização dos bens culturais, a biblioteca é desafiada a abrir-se para atender a todos, sem distinção. Na mesma direção, a escola também passou por uma ampliação de acesso, e tem atendido diferentes grupos sociais, constituindo-se como instituição fundamental no processo de aproximação de diferentes sujeitos da cultura letrada.

No Brasil, nas últimas décadas, novos desafios educacionais são postos em relação à leitura, à sua aprendizagem, e em relação à formação do leitor. Nesse sentido, a biblioteca no espaço da escola tem progressivamente ocupado um lugar privilegiado e de grande valor pedagógico, e vem se consolidando como uma importante ferramenta para o desenvolvimento de práticas leitoras e para o acesso à informação.

Nos últimos anos, notam-se avanços significativos nessa área, sobretudo no que tange ao desenvolvimento de políticas públicas visando à sua melhoria: como o Programa Nacional de Biblioteca Escolar - PNBE - e a Lei $n^{0} 12.244$, sancionada em 2010, que prevê a universalização das bibliotecas escolares no Brasil até 2020. No entanto, conforme apontam dados de pesquisas, como as apresentadas nos artigos que compõem este dossiê, ainda permanecem grandes desafios relacionados à ausência tanto de biblioteca nas escolas e/ou da precariedade desses espaços quanto de profissionais bibliotecários e professores - que efetivamente criem as condições para que se cumpram as funções educativas delas esperadas na escola e na sociedade contemporânea.

Conhecer esse cenário permite deslindar a realidade e o cotidiano de bibliotecas escolares em diferentes locais e regiões do país e fomentar o debate, com o intuito de que sejam construídas estratégias mais adequadas para o seu uso e sua dinamização. Esse é o objetivo deste dossiê, composto de nove artigos, escritos por pesquisadores brasileiros. A maior parte desses artigos apresenta resultados de pesquisas que oferecem indicativos da diversidade de realidades presentes no Brasil; também evidenciam 
recorrências, especialmente, em relação a desafios a serem enfrentados tanto localmente quanto como política pública do estado brasileiro.

No primeiro artigo, “Biblioteca escolar: o que é?”, as autoras Marília de Abreu Martins de Paiva e Adriana Bogliolo Sirihal Duarte definem a biblioteca escolar a partir das categorias dos parâmetros do Grupo de Estudo em Biblioteca Escolar da Universidade Federal de Minas Gerais (GEBE/UFMG) e das suas duas principais funções educativas: a promoção da prática da leitura e das competências informacionais. As autoras exploram diferentes publicações e documentos internacionais, especialmente os produzidos pela International Federation of Library Associations and Institutions - IFLA - e apresentam algumas definições de biblioteca escolar e as diferentes funções que lhe são atribuídas nesse contexto. Ressaltam a importância de os estudos sobre biblioteca escolar apresentarem definição teórica clara e categorias de análise adequadas, para que se evitem reiteradas descrições de realidades sem a necessária reflexão que favoreça avanços em relação à realidade observada.

Em seguida, os autores Mônica Correia Baptista, María Emilia López e José Simões de Almeida Júnior, no artigo "Bebetecas nas instituições de Educação infantil: espaços do livro e da leitura para crianças menores de seis anos”, discutem a constituição de Bebetecas a partir de três experiências distintas: em um jardim maternal, localizado em Buenos Aires; como política pública, em um município brasileiro; na Faculdade de Educação de uma Universidade pública brasileira. Abordam a concepção de leitura e questões relativas à constituição e ao uso do acervo, bem como às mediações a serem efetivadas entre crianças e livros, considerando as especificidades das crianças de zero a seis anos de idade. Concluem que a constituição desse espaço deve levar em conta o fato de essas crianças ainda não dominarem convencionalmente a leitura e a escrita, e reiteram a importância de intervenções e de mediações que favoreçam os processos de apropriação e de exploração dos livros pelos pequenos leitores.

No terceiro artigo, “Acervos de Bibliotecas Escolares e formação de pequenos leitores”, os autores Hércules Corrêa, Renata Junqueira e Berta Lucia apresentam e discutem resultados da pesquisa "Literatura e primeira infância: dois municípios em cena e o PNBE (Programa Nacional Biblioteca da Escola) na formação de crianças leitoras”, realizada em escolas de educação infantil do Oeste Paulista. As reflexões apresentadas no artigo nos dão pistas de como as crianças da primeira infância têm acesso aos livros de literatura infantil nas instituições escolares, de como se dão as práticas de leitura literária nessas instituições educativas e de como seus professores realizam ações de mediação de leitura. Os autores concluem que as atividades para formar os leitores são esparsas e não favorecem o manuseio do livro como objeto cultural. Destacam também que os responsáveis pelas bibliotecas não conhecem os acervos recebidos, não se veem como mediadores de leitura e não consideram a biblioteca como um espaço para aproximar livros e crianças. 
O artigo de Cristiane Dias, intitulado "Espaços públicos de leitura: as bibliotecas escolares do município de Codó/MA”, apresenta e analisa dados de um mapeamento que buscou identificar a existência de bibliotecas escolares e as condições de funcionamento desses espaços no município maranhense. Considerando que as escolas do município recebem acervos do Programa Nacional Biblioteca da Escola, a autora problematiza uma realidade bastante desafiadora, que se caracteriza pela inexistência e/ou pela precariedade de espaço físico para a recepção e a disponibilização dos acervos aos alunos, dificuldades enfrentadas por gestores para receber os acervos nas escolas mais distantes da sede do município, além de ausência de profissionais que façam mediações que favoreçam o contato dos alunos com os livros e a desejada formação de leitores.

Os autores Rejane Sales de Lima Paula, Clarides Henrich de Barba, Aurineide Alves Braga e José Lucas Pedreira Bueno, no artigo “O papel educativo da Biblioteca Escolar”, analisam a representação educativa da biblioteca escolar do ponto de vista dos professores e dos alunos de uma escola de ensino fundamental localizada no município de Porto Velho - Rondônia. Para isso, balizam suas reflexões em uma pesquisa de campo e em dados coletados por meio de um questionário realizado com esses sujeitos. Na realidade pesquisada, os dados permitiram inferir que a biblioteca da escola é um lugar ativo, ou seja, é frequentada pela sua comunidade escolar e é considerada tanto pelos professores quanto pelo responsável pela biblioteca e pelos alunos como um dos principais espaços para o desenvolvimento de atividades de ensino-aprendizagem.

O artigo "Programa Nacional Biblioteca da Escola e a formação de leitores no contexto escolar no município de Hortolândia, SP”, de autoria de Samuel Mendonça, Maria Silvia Pinto de Moura Librandi da Rocha e Kelly de Oliveira Borges de Lima, apresenta dados de pesquisa que buscou apreender a percepção de professores e de gestores sobre possíveis contribuições do Programa para a formação de leitores em três escolas do município em foco. Os autores problematizam questões como a falta de conhecimento, especialmente dos gestores, sobre o PNBE, e a falta de profissionais para atuarem nas bibliotecas, de modo a mobilizar os acervos recebidos e a realizar atividades voltadas para a formação de leitores. Apontam também que, apesar dos problemas observados e de certa desinformação, há uma visão bastante positiva sobre o Programa.

As autoras Leila Barros e Carolina Teixeira de Paula, no artigo "Biblioteca escolar na Rede Municipal de Educação de Belo Horizonte: avanços e possibilidades”, apresentam e analisam uma experiência longeva e bem-sucedida: o Programa de Bibliotecas da Rede Municipal de Educação de Belo Horizonte (RMEBH), suas diretrizes e orientações para o trabalho nas bibliotecas escolares municipais. As autoras destacam os avanços observados desde o início do Programa, em 1997, e os desafios que ainda permanecem ao longo de quase vinte anos de existência, tanto no que se refere à necessária articulação entre biblioteca e práticas pedagógicas desenvolvidas 
em sala de aula quanto à automação das bibliotecas, garantia da presença e formação dos profissionais que atuam nas bibliotecas escolares, de modo a favorecer mediações mais favoráveis à formação do aluno leitor e à construção do hábito de frequentar a biblioteca desde a educação infantil.

O artigo "Leitura, informação, lazer e ludicidade nas bibliotecas escolares: contribuições da Biblioteca Mário de Andrade/SP”, de autoria de Magali dos Reis e Vânia Noronha Alves, traz indagação e reflexões sobre a constituição e o papel social e cultural da biblioteca na formação das diferentes gerações. As autoras apresentam análises sobre o surgimento da biblioteca e a especificidade das bibliotecas escolares, consideradas espaços de aquisição e de produção de conhecimento, potencial equipamento de lazer e de cultura para educandos e para a comunidade em que se inserem. Como referência para as reflexões sobre as potencialidades das bibliotecas escolares, as autoras apresentam experiências observadas na Biblioteca Mário de Andrade (BMA), situada na região oeste da cidade de São Paulo, e concluem que é necessário discutir a função da biblioteca na escola e a mobilização para sua organização e para o seu funcionamento, favorecendo o encontro com os interesses do educando de formação também para outras dimensões da vida, além do trabalho.

Fechando o dossiê, o artigo "Bibliotecas escolares nas Escolas Normais no Brasil: constituição do lugar e dos sujeitos”, de Ana Clara Bortoleto Nery, analisa o processo de criação e de instalação de bibliotecas escolares nas Escolas Normais criadas no século XIX, a partir da legislação, de pesquisas realizadas e de indícios de funcionamento das bibliotecas. A autora analisa o funcionamento das bibliotecas a partir de dois ângulos: o do bibliotecário e o das condições criadas para as práticas de leitura desenvolvidas nessas escolas. Revela que a instalação de bibliotecas escolares nas Escolas Normais passa por processos diversos devido às particularidades de cada localidade. Ainda destaca que esse processo resultará numa importância maior do livro dentro e fora do espaço escolar.

Os trabalhos que compõem este dossiê apresentam diferentes perspectivas, abordagens e questões que nos interpelam e nos interrogam sobre as funções da biblioteca no ambiente escolar. Tais reflexões sinalizam um esforço de compreender o papel da biblioteca escolar, sua potencialidade como instância de formação do leitor na escola e os desafios postos para gestores, profissionais da educação e pesquisadores, para que, efetivamente, toda escola pública brasileira tenha bibliotecas com boa estrutura física, acervos atualizados, profissionais formados e com condições favoráveis de desenvolverem um trabalho voltado para a formação do leitor no ambiente escolar. Certamente, essa realidade só poderá se concretizar por meio de políticas públicas efetivas que garantam a ampliação do direito à educação de qualidade e o acesso a informações e a bens culturais como o livro. Boa leitura!

Santuza Amorim da Silva Maria José Francisco de Souza 